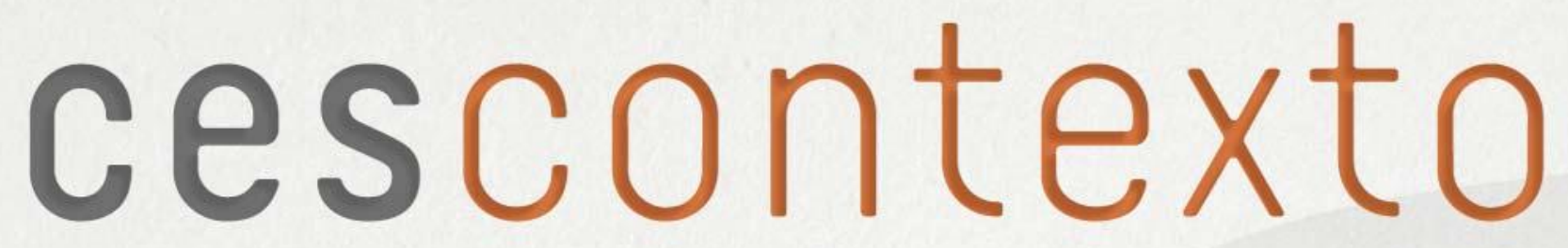

Bibliotecas públicas, políticas culturais e leitura pública

Organização

Paula Sequeiros

Nuno Medeiros

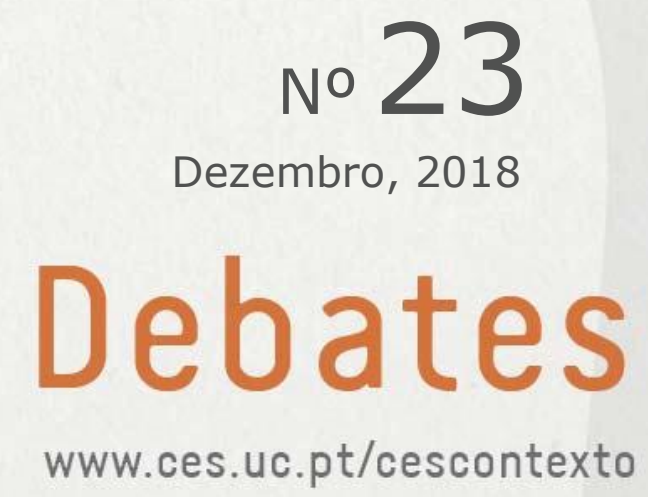




\section{Propriedade e Edição/Property and Edition}

Centro de Estudos Sociais/Centre for Social Studies

Laboratório Associado/Associate Laboratory

Universidade de Coimbra/University of Coimbra

www.ces.uc.pt

Colégio de S. Jerónimo, Apartado 3087

3000-995 Coimbra - Portugal

E-mail: cescontexto@ces.uc.pt

Tel: +351239855573 Fax: +351239855589

\section{Comissão Editorial/Editorial Board}

Coordenação: Ana Raquel Matos

ISSN 2182-908X

(C) Centro de Estudos Sociais, Universidade de Coimbra, 2018. 
raibliot

Bibliotecas Públicas,

politicas culturais e

leitura pública,

6 e 7 de setembro de 2018

Casa dos Bicos, Fundação José Saramago (iisboa)

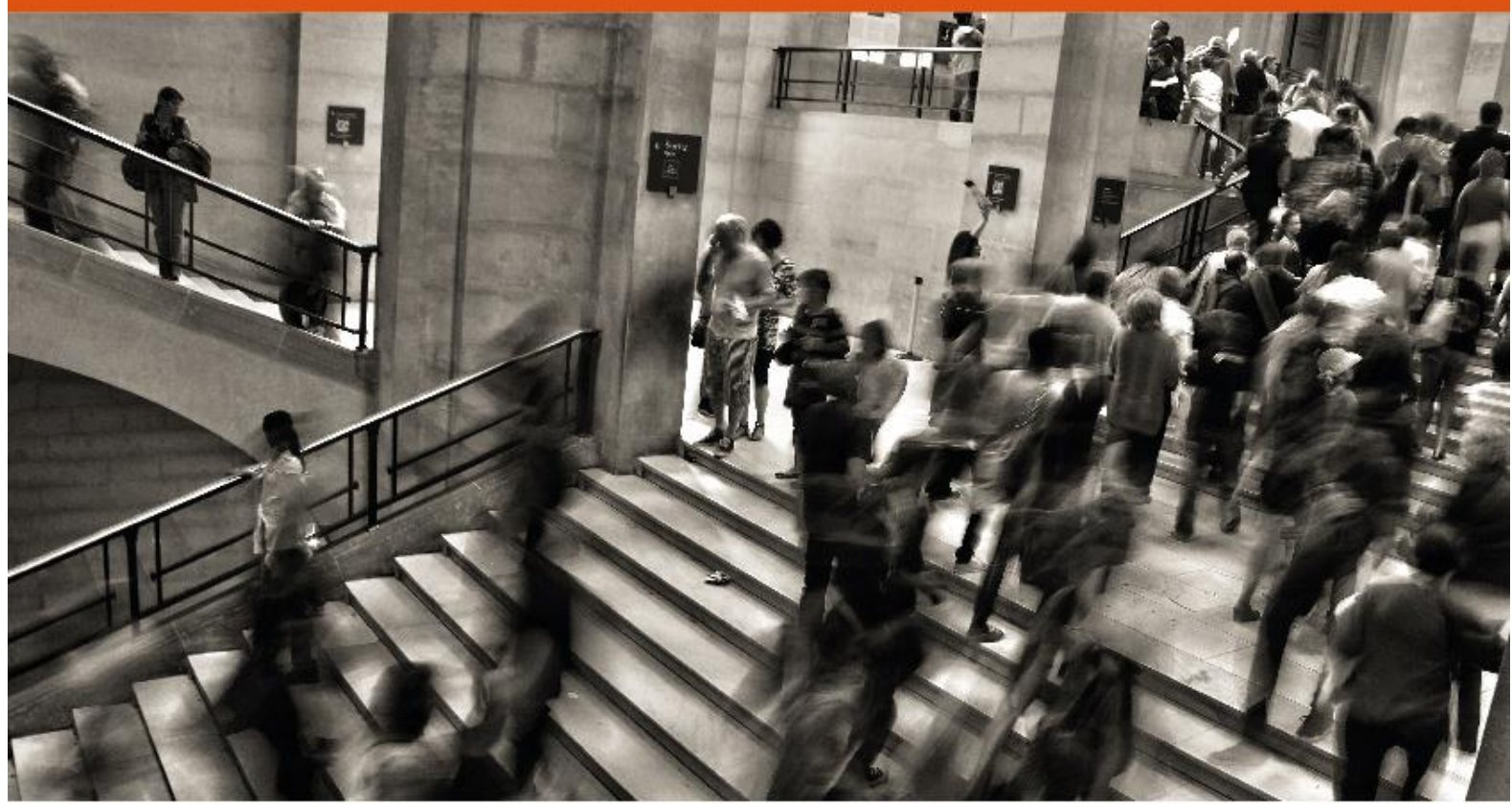

José Martin Ramirez $\circledast$ Unsplast

Inscricões abertas em ces.uc.pt/eventos/bibliotecas-publicas

apresentadoras/es 20 julho a 28 julho 2018 participantes 30 julho a 17 agosto 2018

10 Centro de Estudos Sociais Centre for Social Studies

CeS Universidade de Coimbra University of Coimbra

CESIAIta

CESI Sofia CES I Lisboa

$\begin{array}{lll}\text { Colégio de S.Jerónimo } & \text { Colégio da Graça } & \text { Picoas Plaza } \\ \text { Apartado } 3087 & \text { Rua da Sofia, 136-138 } & \text { Rua Viriato, 13 Li 117/118 } \\ \text { 3000-995 Coimbra } & 3000-389 \text { Coimbra } & \text { 1050-227 Lisbo }\end{array}$

Apartado 3087

Rua Viriato, 13 Lis $1050-227$ Lisb

$\begin{array}{lll}\mathrm{T}+351239855570 & \text { Portugal } & \text { Portugal } \\ & \mathrm{T}+351239853649 & \mathrm{~T}+351216012848\end{array}$

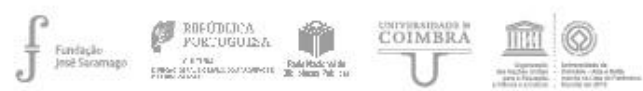

ces.uc.pt

Fotografia de José Martín Ramírez C, Unsplash. 


\section{Agradecimentos}

A Conferência Internacional Bibliotecas Públicas, Políticas Culturais e Leitura Pública, organizada pelo CES, Universidade de Coimbra (UC), ocorreu em Lisboa, de 6 a 7 de setembro de 2018, na Casa dos Bicos, Fundação José Saramago. A realização contou com o apoio de:
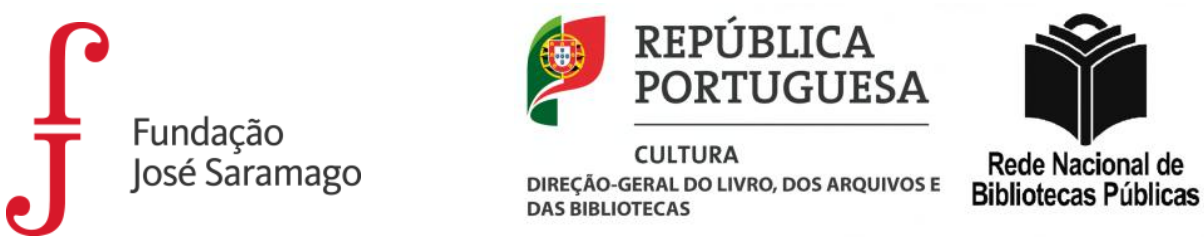

\section{C.MPETE $2020 \$ 2020$}




\section{Índice}

Paula Sequeiros e Nuno Medeiros

Que faremos com estas bibliotecas?

Rui Matoso

O contributo das bibliotecas públicas para a efetivação da democracia cultural.

Margarita Pérez Pulido e Maurizio Vivarelli

La identidad de la biblioteca pública y el campo de la biblioteconomía social.

Maria Manuel Alves Rijo

Como envolver a comunidade com a Biblioteca através da arte?

Débora Dias

Do privado ao público: a biblioteca pessoal e suas metamorfoses

Carla Silva

A Biblioteca do Liceu Alexandre Herculano no Porto: entre políticas estigmatizantes e uma estratégia de mobilização social.

Paula Sequeiros

Na biblioteca pública, ler por prazer: uma mirada feminista 82 


\title{
Na biblioteca pública, ler por prazer: uma mirada feminista
}

\author{
Paula Sequeiros, ${ }^{1}$ Centro de Estudos Sociais, Universidade de Coimbra \\ psequeiros@ces.uc.pt
}

Resumo: O prazer da leitura, declarado por leitoras e leitores diversos e em diversas circunstâncias, não parece ter um assento simples no contexto da leitura pública. Proponho indagar um desajustamento entre modos desejados de leitura, em torno do prazer leitural, e os lugares da sua prática em bibliotecas públicas. Dadas as marcas patriarcal e produtivista nos constrangimentos históricos ao prazer de ler, proponho partir de um quadro teórico feminista orientado para o questionamento do contentamento proporcionado pela leitura, enquanto forma de trabalho reprodutivo, dos cuidados. Pretendo lançar algumas bases que permitam esclarecer a forma presente desses constrangimentos assim como compreender como se pode produzir um lugar praticado de leitura pública que reconheça e acolha esse modo leitural.

Palavras-chave: leitura pública, leitura por prazer, perspetivas feministas, moralismo, contentamento.

Ler simplesmente por prazer.

A primeira reação é de estranheza: fundamentar porque a leitura por prazer pode e deve ter lugar em bibliotecas públicas assemelha-se, a meu ver, a um contrassenso.

Se o prazer na leitura é corrente, legítimo, se é expectável pelo menos para a leitura privada, não é frequente que as bibliotecas de leitura pública se ofereçam como um lugar explicitamente marcado para a sua concretização. Seja através do escrutínio das políticas de leitura aplicadas a esses espaços, seja pela perceção da cultura institucional ou das atmosferas de leitura (Sequeiros, 2011) de muitas delas, a questão ganha corpo. Comparativamente, a leitura mais marcada por fins utilitários, como a dirigida à aprendizagem ou à informação proporcionada pelos jornais, parece ser uma prática que, em geral, não carece de justificação.

Neste trabalho, proponho perguntas e avanço um enquadramento teórico dirigido ao questionamento da desejabilidade da leitura por prazer naqueles espaços institucionais. Seleciono e articulo conceitos e abordagens que se me afiguram frutíferos.

Para compreender se existe esse lugar marcado, não partirei tanto da perplexidade, já que muitas possíveis respostas ressoam face a essa questão, aparentemente ingénua e deslocada. Partirei antes da insatisfação percecionada nas próprias práticas de leitura pública dirigidas ao prazer leitural, de relatos sobre as suas condições, num contexto de instituições que reúnem, contudo, potencial para tanto.

Entendo por biblioteca pública desejável um espaço propício para conjugar as dimensões leiturais estéticas e prazerosas, da imaginação e da criação, da reparação corpórea e da convivialidade, no âmbito das práticas quotidianas mais correntemente associadas ao lazer e à cultura.

\footnotetext{
${ }^{1}$ Investigadora do Centro de Estudos Sociais (CES) da Universidade de Coimbra. Pesquisa na área das bibliotecas públicas e novas tecnologias, bibliotecas públicas e leitura. Pós-doutoranda no CES com o projeto "A biblioteca no tempo: bibliotecas dos paradigmas do impresso, do oral e do digital", 2017. Licenciatura em História, Universidade do Porto; Mestrado Sociedad de la Información y del Conocimiento, UOC; Doutoramento em Sociologia, Universidade do Porto. Foi documentalista em empresas e bibliotecária em instituições do ensino superior. Trabalhos depositados em http://eprints.rclis.org/.
} 
O quadro teórico que adianto dirige-se ao questionamento do que é a leitura prazerosa. A partir deste quadro, evidenciarei os constrangimentos da moralidade produtivista e patriarcal às práticas leiturais por prazer. Convocarei miradas feministas sobre as possibilidades da leitura como território de imaginação, reparação, recreação e contentamento.

a partilha da alegria, ${ }^{2}$ seja física, emocional, psíquica ou intelectual forma uma ponte entre quem partilha que pode ser a base para compreender muito do que não é partilhado entre essas pessoas e diminui a ameaça da diferença (Lorde, 1984:56)

Invocarei, por fim, a desejabilidade de um lugar que ofereça essas possibilidades dentro das bibliotecas.

Destaco de seguida conceitos centrais para esta reflexão.

\section{Abordagem concetual}

\section{Práticas e espaços: leitura, pública e privada}

Começarei por caraterizar a leitura pública como aquela que se frui em espaços públicos de leitura, a partir de objetos, materiais ou não, e de serviços disponíveis em bibliotecas de acesso público. As práticas de leitura nesses espaços produzem diversos lugares leiturais, operando uma fusão entre, por um lado, um espaço de leitura individual, íntimo (Petit, 2001), e, por outro, um espaço social, de fruição coletiva de bens organizados em torno da escrita e da leitura. A este artifício analítico, de separação entre as dimensões pública e privada da leitura, farei referência de seguida.

Mesmo que produzida em espaço público, a leitura revela traços da prática individual, interpretativa e concentrada no objeto de leitura, prática que acrescenta uma outra camada espacial ao cruzamento entre o espaço social e o físico: lendo, o corpo parece ausentar-se do seu lugar e, sem desancorar, flui para o lugar singular recriado pela leitura. A este espaço leitural, chamou Michèle Petit "íntimo", não "público", realçando que se pode constituir como uma saída das "prescrições familiares ou sociais", em qualquer idade ou condição social, incluindo uma saída de condições físicas muito adversas (2001, 42-43). Esse lugar íntimo da leitura tem sido especialmente escrutinado pelo moralismo conservador e patriarcal.

As representações sobre o ato de ler convocam, provavelmente em primeiro lugar, o espaço privado, as imagens domésticas da leitura. Por aí começo.

Jeannette Winterson usou para um dos seus títulos uma curiosa analogia em Oranges are not the only fruit enfatizando como viveu conflitos agudos em torno das prescrições familiares e o seu desejo de explorar outras formas de viver. Apaixonada defensora das bibliotecas, Winterson pronunciou-se publicamente nos momentos em que os poderes locais encerraram mais de seiscentas bibliotecas de bairro no Reino Unido. E explicou em entrevista a um jornal (2012):

Eu costumava dar uma ajuda na biblioteca. Era uma miúda bruta e dura, não muito boa na escola, a não ser com as palavras. Tínhamos seis livros em casa, mas eu tinha a biblioteca. Adorava aquele edifício construído para as classes trabalhadoras - construído para mim. Adorava a sensação de tranquilidade energética. Quando saí de casa aos 16 e vivi dentro de um Mini, ia para a biblioteca a noite toda até fechar.

Não pretendendo abordar as questões do gosto na leitura, entendo ser imprescindível, contudo, um percurso pelas representações sobre a leitura como lugar privado, marcado por constrangimentos, particularmente pelos de género, como referirei. Acontece ser o doméstico, frequentemente, um lugar de violência, física e simbólica, sobre quem deseja ler livremente,

\footnotetext{
${ }^{2}$ Tradução própria do original para este extrato de texto e seguintes. Joy traduzido como alegria, aqui e subsequentemente.
} 
como aquela miúda. A biblioteca pública que não integre fortes limitações à liberdade de ler pode adicionar, em comparação, oportunidades de abertura a vidas encerradas.

Quando inserida em contexto público ou de serviço público, a leitura é também demarcada por constrangimentos e facilitações, desde os dos conteúdos disponibilizados provavelmente mais notórios -, aos dos modos de leitura esperados, cultural e institucionalmente acolhidos, e propiciados pela configuração dos espaços constrangimentos estes de leitura mais subtil. Quem lê, perceciona o seu possível lugar a partir de pistas corporizadas, aparentes. A hexis corporal dominante - posturas, atitudes, maneiras de estar - (Bourdieu, 1977, 87) em cada área da biblioteca é contrastada com os habitus próprios de quem entra. O social evidencia-se a partir das pistas corporizadas de género, de classe, racializadas, as quais tacitamente pontuam a adequação, ou não, da pessoa que quer ler. No quadro da cultura institucional, das políticas de leitura locais ou gerais, há contudo lugar para algumas práticas de leitura não conformes, não esperadas nem imaginadas e que poderão ser aceites, toleradas. A ação individual ou grupal pode criar lugares praticados imprevistos, como sinalizei em pesquisa baseada em observação numa biblioteca pública, desde a deslocação de peças de mobiliário para local mais apetecível, até ao à-vontade para fazer a sesta ou ainda a posição vantajosa de leitoras e leitores frequentes na regulação do ruído e na aceitação de usos imprevistos da Internet (Sequeiros, 2011). Destaco, neste ponto, o conceito de práticas legítimas imaginadas (Bourdieu e Darbel, 1966, 60) em instituições culturais, para questionar se a leitura por prazer é uma prática adequada, esperável, desejável no lugar institucional que a biblioteca é.

A análise da leitura pública requer portanto a consideração integrada do público e do privado, do íntimo e do partilhado, do sensorial, do inteligível, da conformidade e do inesperado. Requer ainda uma atenção particular à normatividade não explícita, tacitamente produzida no decurso das sociabilidades leiturais.

\section{Criar o lugar da e pela leitura}

A leitura, logo enquanto lugar de prática, pode constituir-se como transgressão, tanto pelo que se lê como pela capacidade de evasão de um espaço controlado para um outro criado pela pessoa leitora. Na visão de Michèle Petit $(2001,51)$ :

Uma vez que que a alegria é um sentimento que nos eleva acima do quotidiano, não podemos facilmente andar à sua procura, mesmo que consigamos adquirir formas rotinizadas de escapar à ansiedade ou às fontes de tristeza. O contentamento é certamente uma emoção mais simples de compreender, enquanto que a alegria raramente pode ser prevista.

Adotarei a sua visão pelas possibilidades que oferece para pensar o prazer de ler, prazer particular que entendo situar-se entre a alegria e o contentamento. Outro traço, relevante para compreender a leitura pública, em companhia, é o destaque dado às várias manifestações de felicidade como produto da vivência social. Momentos fortes de contentamento, que Segal trata com detalhe, pressupõem um sentimento de união ${ }^{3}$

A oportunidade para gozar de companhia de outras pessoas igualmente envolvidas na leitura, numa atmosfera de grupo, foi tratada antes por Maria Bakardjieva (2004) a partir de uma motivação frequente para a ida às bibliotecas, mesmo para quem possuía livros em casa. Este sentimento de união não perturbava o espaço pessoal da leitura, a coprodução de um lugar leitural antes o estimulava. Uma parte do leitorado que visita a biblioteca pública procura um espaço onde possa "estar com", observar e sentir pessoas igualmente ocupadas e reunidas numa mesma prática, como analisei em pesquisa etnográfica numa biblioteca

\footnotetext{
${ }^{3}$ Togetherness no original; tradução que reterei para textos de outras autoras.
} 
pública. Essa forma de união, em interação sem intrusão, nem proximidade vicinal ou familiar, facilita a concentração, impulsiona a ler. O encontro com quem é diferente, quebra isolamentos e reconforta. Isto é, do meu ponto de vista, o que Winterson referiu como tranquilidade energética. Por tudo isso vários leitores e leitoras da biblioteca pública liam melhor dentro da biblioteca, se comparada com espaços outros de isolamento (Sequeiros, 2010).

As questões que emergem, assim, no decurso desta reflexão são: há lugar para a leitura prazerosa nas bibliotecas públicas? Em caso de resposta afirmativa, como se poderá produzir esse lugar? E ainda, como se apresentam esses modos leiturais?

Para completar esse enquadramento torna-se necessário abordar ainda os constrangimentos à leitura orientada para o prazer.

\section{As três pechas: o perigo social, a imoralidade, a inutilidade}

Representações e narrativas sobre a leitura na sua relação com os padrões da conformidade social contêm, impressas, marcas genderizadas de moralismo de género e pelos imperativos produtivistas. Por ter permanecido um campo histórico de transgressão hiperbolizada e de prescrição afinada, a leitura de mulheres é o ponto de ancoramento inicial para o questionamento que proponho. Tomarei por base alguma reflexão produzida sobre esse campo, apostando na sua capacidade interpretativa em relação a modos não conformes, transgressores de leitura pública.

Em décadas passadas, o termo então em voga de leitura amena - também usado em bibliotecas - exprimia, pelo menos parcialmente, o conceito de leitura por prazer, ao designar práticas de leitura não utilitárias e sem fins produtivos. E esta forma de apropriação leitural estava associada à leitura por mulheres.

Para Portugal, sabemos pouco sobre como leem elas em bibliotecas públicas na atualidade. Percebeu-se que a percentagem que comprava livros há alguns anos era significativamente superior à dos homens (Neves e Lima, 2008; Neves, 2011), em linha com dados homólogos europeus. Ler na biblioteca, muda o contexto da prática e não é claro, face à lacuna estatística, que as mulheres predominem como visitantes ou leitoras. A observação que conduzi em bibliotecas públicas não o confirmou (Sequeiros, 2010; Sequeiros e Grünig, 2012).

É relevante lembrar a perspetiva de Bernard Lahire de que, a diferença entre sexos na leitura, é mais proficuamente observada através dos diferentes modos de apropriação da leitura do que pela quantificação de obras lidas (1998: 217-219). Importa também ter em conta a sua chamada de atenção para o facto de não ser a diferença genderizada na escolarização tão esclarecedora, em termos comparativos, como a distribuição genderizada de papéis sociais na família e na sociedade (Lahire, 1993).

Referir-me-ei de seguida a três rotulagens que têm vindo a ser apostas à leitura de e para mulheres.

\section{O perigoso, o imoral}

A leitura permite uma certa forma de "ubiquidade", o espaço criado pela leitura pode constituir-se como uma "ausência impertinente" (Rosolato, apud Certeau, 1990: 250). É esta impertinência que certamente produz a irritação de agentes sociais que aspiram a controlar as públicas virtudes. O lugar indeterminado da leitora, refúgio ou transgressão, cristalizou-se em décadas passadas nas imagens de mulheres jovens e maduras entregues à leitura do romance, em áreas privadas e íntimas, em posturas ambíguas de abandono e sedução por um objeto leitural que competia com o privilégio da masculinidade patriarcal. 
O romance foi ele próprio objeto vigiado e suspeito pelo público a que se dirigia sobretudo feminino - e pelas paixões que teria capacidade de incendiar. Alvo particular do escrutínio moral, se fora do espaço doméstico e emocionalmente fora ainda de um controle subordinante, a imagem da mulher letrada, das classes médias, absorta pelo romance, fez-se sinédoque da leitura perigosa com uma cristalização histórica surpreendente (Vaquinhas, 2010). A ênfase na leitura como forma de apropriação individual, é central na obra precursora de Janice Radway (1984). Esta criticou detalhadamente o olhar patriarcal sobre a leitora de romances, enfatizando a diversidade e a complexidade das formas de apropriação, as quais incluíam dimensões recreativas, de experiência e aprendizagem vicarial, sublinhando o enraizamento social dessas apropriações e descentrando do enfoque no escapismo, na superficialidade e na hiperemocionalidade.

Entender a leitura como trabalho de cuidado, a par de outras formas de reparação do corpo, proporciona ainda a ultrapassagem de uma abordagem medicalizadora aos benefícios da leitura a qual tem recebido crítica pontual (Barone, 1977). A retórica clínica sobre o contentamento, visto como terapia quando associado à fruição cultural e à recreação, tem recentemente encontrado nova formulação. Caraterizar largos números de indivíduos como sofrendo de depressão, carentes de autoajuda, como observa Segal (2018), tem o seu equivalente histórico na caraterização da nostalgia que teria tomado posse de algumas cabeças nas sociedades ocidentais há décadas atrás. Os modos de vida das sociedades capitalistas contemporâneas engendram tropismos e rotulagens provenientes de taxonomias orientadas para individualizar e penalizar uma morbilidade - em alastramento - que tem antes uma origem societal.

\section{O inútil}

Produtivismo e leitura como prática de lazer, fora da esfera produtiva, não parecem conjugarse. Refere Barthes, em O prazer do texto, todo um leque de opositores à fruição do texto, insistentemente mas sem surpresa, "sendo improdutivo o prazer" (1970: 70). Frequentemente se encobre em público o prazer simples da leitura com uma capa de dignidade, literalmente o caso das capas especiais na reedição para adultos da série Harry Potter. ${ }^{4}$ Observei, ainda, como alguns estudantes apresentavam finalidades sérias para as suas estadias numa biblioteca pública, colocando livros de estudo e dicionários sobre as mesas, não assumindo, por crerem ser prática aí desaconselhada, a consulta de objetos de leitura como mensagens pessoais ou livros não escolares trazidos consigo.

O reconforto retirado da leitura, integra expectavelmente as narrativas de leitores assíduos e torna-se referência destacada em condições de vida adversas. Pensar a leitura como uma forma de trabalho dos cuidados, de cuidado de si, é uma interessante perspetiva:

Assim a construção de si pela leitura leva a inscrever-se em formas de sociabilidade diferentes das sociabilidades ligadas às socializações primárias e secundárias. A entrada na leitura coletiva vai desde logo contribuir para o desenvolvimento de um sentido prático que se pode qualificar de cuidado de si pela leitura. Este cuidado de si, porque é cultivado na e para a leitura, aparece indissociavelmente ligado ao cuidado das e dos outros (Albenga, 2011: 93).

São conhecidas experiências de situações críticas em que, mesmo estando em falta a satisfação das chamadas necessidades básicas, em condições extremas de emocionalidade abalada, a leitura proporciona reparação, como mostram os casos de leitura em condições extremas. Entre estas, estão a prisão política (Oliveira, 2011) ou comum feminina (Sequeiros, 2018), as ocupações do espaço público por movimentos de protesto (Bidgood, 2011; Pérez

\footnotetext{
${ }^{4}$ Ler mais em "See Harry Potter book covers through the years" de 2018, por Madeline Boardman, em Entertainement, https://ew.com/gallery/harry-potter-book-covers/.
} 
Martín, 2011). Pela ancestral alocação do trabalho dos cuidados às mulheres, e ainda pela possibilidade de passar, a partir de uma reflexão feminista para uma esfera mais pública, entendo que é especialmente desafiante tomar esta ponta do fio.

Por fim, o facto de se estar perante a prestação de um serviço público, de leitura neste caso, pode, nas presentes condições socio-políticas, agravar uma valorização negativa dessa prestação, alegando-se não ser a leitura um serviço básico que responda a uma necessidade universal, ou alegando a ilegitimidade de financiar públicos vícios. Embora dificilmente verbalizado nestes precisos termos, a expressão financeira nos orçamentos das bibliotecas fala sobre a relevância que lhes é atribuída pelo poder central e local. Durante os anos recentes da intervenção da Troika, várias bibliotecas tiveram as aquisições de novos livros fechadas, apesar da observável persistência ou aumento das visitas de leitoras e leitores.

\title{
A leitura como território de imaginação, reparação, recreação e contentamento
}

Reconhecendo a dificuldade de discorrer sobre o prazer sem resvalar para o moralismo e as prescrições de comportamento, tomo emprestadas as palavras de Audrey Lorde (1984: 59), claras e incisivas:

\begin{abstract}
Só agora encontro cada vez mais mulheres que se identificam como mulheres, com a bravura suficiente para arriscarem partilhar o que é a carga elétrica do erótico, sem terem de desviar o olhar e sem distorcerem a natureza enormemente poderosa e criativa dessa troca. Reconhecer o poder do erótico nas nossas vidas pode dar-nos a energia para procurar uma mudança genuína no nosso mundo, em vez de somente nos conformarmos com uma troca de personagens no mesmo drama estafado. Porque não só tocamos a nossa fonte mais profundamente criativa, como fazemos aquilo que é feminino e autoafirmativo face a uma sociedade racista, patriarcal e anti-erótica.
\end{abstract}

A conhecida associação freudiana do prazer ao erotismo, pode facilitar a compreensão das reações adversas ao prazer na leitura - conotado com o feminino - em parte, certamente. Associar o de prazer de ler à imaginação, e esta à abertura para cenários alternativos de vida não terá, espero, menos capacidade explicativa.

O que me proponho é seguir estas trilhas em pesquisa futura, tomando a leitura pública como prática social em que o cuidado de si se inscreve como uma dimensão do trabalho reprodutivo, entendendo de que forma esse trabalho de cuidado se articula com a imaginação, a reparação corporal, a recreação e o contentamento de quem lê e, por fim, de que forma esse cuidado mediado pela leitura encontra um lugar à disposição em bibliotecas públicas.

\section{Referências bibliográficas}

Albenga, Viviane (2011), "Devenir soi-même"” par la lecture collective: une approche antiindividualiste', Culture \& Musées, (17), 85-106. Consultado 16-12-2018, disponível em https://doi.org/10.3406/pumus.2011.1598.

Bakardjieva, Maria (2004), "Virtual togetherness: an everyday life perspective." in Community in the digital age: Philosophy and practice (Ed.), Andrew Feenberg e Darin Barney. Lanham: Rowman \& Littlefield, 121-142.

Barone, Richard M. (1977), "De-programming prison libraries", Special Libraries, 68(9), 293-298. 
Bidgood, Jess (2011), “Tent libraries occupy Boston and beyond”, The New York Times, 21 October. Consultado 16-12-2018, disponível em https://www.nytimes.com/2011/10/22/us/tent-libraries-occupy-boston-and-beyond.html.

Barthes, Roland (1973), Le plaisir du texte. Paris: Seuil.

Bourdieu, Pierre (1977), Outline of a theory of practice[ Vol. 4]. Cambridge: Cambridge University Press.

Bourdieu, Pierre; Alain Darbel (1966), L'amour de l'art: les musées et leur public. Paris: Les Éditions de Minuit.

Certeau, Michel de (1990), L'invention du quotidien: art de faire [2a ed]. Paris: Gallimard.

Lahire, Bernard (1993), La raison des plus faibles: rapport au travail, écritures domestiques et lectures en milieux populaires. Lille: Presses Universitaires de Lille.

Lahire, Bernard (1998), L'homme pluriel: les ressorts de l'action. Paris, Nathan.

Lefèbvre, Henri (2000), La production de l'espace. Paris: Anthropos.

Lorde, Audre (1984), "Uses of the erotic: the erotic as power", in Sister outsider. Freedom, CA: Crossing.

Neves, José (2011), Práticas de leitura da população portuguesa no início do século XXI. Tese de doutoramento. Lisboa: ISCTE. Consultado 16-12-2018, disponível em https://repositorio.iscte-iul.pt/handle/10071/6696.

Neves, José, Lima, Maria João (2008), “A leitura em Portugal: perfis e tipos de leitores”, in Mundos sociais: saberes e prácticas, 10. Consultado 16-12-2018, disponível em https://dialnet.unirioja.es/servlet/articulo?codigo $=4536512$.

Oliveira, Eliana Catarina Gonçalves de (2012), Aljube, uma cadeia política. Tese. FCSH, Universidade Nova de Lisboa. Consultado 16-12-2018, disponível em https://run.unl.pt/handle/10362/9390.

Pérez Martín, Miguel (2011), "Los indignados del movimiento 15-M se levantan bajo el lema 'No nos vamos, nos expandimos." El País, Junio 12. Consultado 16-12-2018, disponível em https://elpais.com/elpais/2011/06/12/actualidad/1307866617_850215.html.

Petit, Michèle (2001), Lecturas: del espacio íntimo al espacio público. México: Fondo de Cultura Económica.

Radway, Janice (1984) Reading the romance: women, patriarchy, and popular literature. Chapel Hill: University of North Carolina Press.

Segal, Lynne (2018), Radical happiness: moments of collective joy. Brooklyn: Verso.

Sequeiros, Paula (2010), Ler uma biblioteca nas inscrições de leitores, espaço e Internet: usos e representações de biblioteca pública. Tese de Doutoramento em Sociologia. Faculdade de Letras da Universidade do Porto. Consultado 16-12-2018 em http://hdl.handle.net/10760/20396. 
Sequeiros, Paula (2011), "The social weaving of a reading atmosphere", Journal of Librarianship and Information Science, 43(4), 261-270. doi: 10.1177/0961000611425823.

Sequeiros, Paula (2018). “'Holding the Dream' ": women's favorite readings in a Portuguese prison', Qualitative Sociology Review, 14(1), 110-128. doi: http://dx.doi.org/10.18778/17338077.14.1.06.

Sequeiros, Paula e Grünig, Silvia (2012), “A tale of two libraries: space, place and reading in Porto's public libraries", in Lau, Tammaro, e Bothma (eds.) Libraries driving access to knowledge. The Hague: IFLA, de Gruyter, 247-288. Consultado 16-12-2018 em http://www.degruyter.com/view/books/9783110263121/9783110263121.247/9783110263121 .247.xml.

Vaquinhas, Irene (2010), "Perigos da leitura no feminino: dos livros proibidos aos aconselhados (séculos XIX e XX)", Ler História, (59), 83-99. Consultado 16-12-2018 em http://lerhistoria.revues.org/1327.

Winterson, Jeanette (2012), "We must protect and reinvent our local libraries", The Guardian. 23 November. Consultado 16-12-2018, disponível em http://www.theguardian.com/books/2012/nov/23/protect-our-libraries-jeanette-winterson. 